\title{
BINA MASYARAKAT KELURAHAN DALAM RANGKA MENINGKATKAN KUALITAS HIDUP MELALUI PROGRAM PEMERIKSAAN KESEHATAN UNTUK DETEKSI HIPERTENSI
}

\author{
Doti Wahyuningsih dan Sri Herlina \\ Program Studi Pendidikan Dokter, Fakultas Kedokteran \\ Universitas Islam Malang \\ (Email: dotiwahyuningsih@unisma.ac.id; sriherlina@unisma.ac.id)
}

\begin{abstract}
ABSTRAK
Latar Belakang Hipertensi adalah penyakit berbahaya namun demikian timbulnya penyakit dan akibat buruknya bisa dicegah. Penyakit ini sering ada tanpa memberikan gejala yang didasari penderita. "Menjaga kesehatan lebih baik dari pada mengobati" merupakan anjuran yang belum dilaksanakan sepenuhnya oleh individu maupun masyarakat. Menjadi tugas tenaga kesehatan untuk terus memberi dan mengingatkan masyarakat untuk melaksanakan hal tersebut. Salah satu sarana untuk melaksanakan hal tersebut adalah melalui program pemeriksaan kesehatan rutin dan berkelanjutan. Kegiatan dilaksanakan di slah satu kelurahan di Kabupaten Malang.

Tujuan Program ini yaitu untuk mendekatkan pelayanan kesehatan dengan masyarakat dan mendeteksi penyakit-2 utamanya hipertensi.

Metode Pelaksanaan kegiatan di lakukan di Balai Kelurahan, salah satu keluharan di Kabupaten Malang. Peserta berjumlah 150 warga dari $11 \mathrm{RW}$ yang tersebar diwilayah ini. Peralatan yang digunakan adalah: Sphygmomanometer, stetoscope, Timbang badan, alat ukur tinggi badan, kit pemeriksaan kimia darah (pemeriksaan gula darah sewaktu, lemak darah, asam urat), Media cetak (brosur) tentang anjuran hidup bersih dan menjaga kesehatan lebih baik dari mengobati.

Hasil Sebanyak 106 (70,7\%) peserta berusia lebih dari tahun. Sebanyak 48 peserta (32\%) berusia 51-60 tahun. Sejumlah 48 peserta (32\%) adalah penderita prehipertensi (Standar JNC 7). Hipertensi tahap 1 ditemukan pada 20 peserta $(13,3 \%)$, hipertensi tahap 2 terdapat pada 57 peserta (38\%). Empat peserta $(2,7 \%)$ terdiagnosa Diabetes melitus.
\end{abstract}

Kesimpulan. 70,7\% (106) peserta berumur lebih dari 50 tahun. 82, 60\% (124) peserta terdeteksi memiliki hipertensi dan prehipertensi. Kegiatan ini direspon baik oleh masyarakat ditandai dengan kehadiran 150 peserta.

Kata Kunci : Bina masyarakat, pemeriksaan kesehatan, pencegahan hipertensi. 


\begin{abstract}
Background: Hypertention is dangerous but its development and the adverse effects can be prevented. The disease oftenly presents no symptoms and signs to alert. "Maintaining health is better than treating" is a suggestion that has not been fully implemented by individuals or society. It is the duty of health workers to always remind the public to practice it in daily life. A routine and ongoing health screening program were done to fullfil the duty .

Aim:The program also aims to bring health services closer to the community. The activity was carried out at the Kelurahan, one of the neighborhoods in Malang Regency.

Methods: The equipments used in this activity are: Sphygmomanometer, stethoscope, body weight scales, body height gauge, blood chemistry kit (uric acid, blood sugar and fat), Printed media (brochure) about recommended clean life and 'maintaining health is better than treating.

Results: Total participants were 150 residents from $11 \mathrm{RWs}$ spread throughout the region. Seventy two (48\%) participants were 51-60 years old. Fourty eight participants (32\%) were found to have prehypertension (JNC Standard 7). Stage 1 hypertension was found in 20 participants (13.3\%), stage 2 hypertension was found in 57 participants (38\%). Four participants (2.7\%) were diagnosed with Diabetes mellitus.

Conclusion: 106 participants $(70,7 \%)$ were over 50 years old. Almost a half of the participants (48 or 32\%)were 51-60 years old.124 participants $(82,60 \%)$ were detected to have hypertension and potential to develope hypertension (prehypertension). Number of participants (150) of this health activities indicated a good respond of residents of the Kelurahan toward the activities.
\end{abstract}

Keywords: Community development, health checks, prevention of hypertension

\section{PENDAHULUAN}

Permasalahan yang dihadapi di Indonesia sepuluh tahun terakhir (triple burden diseases) yaitu masih tingginya penyakit menular dan tidak menular penyakit tidak menular (PTM). Menurut data Kementerian Kesehatan Republik Indonesia, selama bulan Januari hingga Juni

2018, hipertensi menduduki peringkat pertama yang didiagnosa di fasilitas kesehatan sebanyak 185.857 kasus (Sulaiman, 2018). Pada tahun 2016, jumlah kunjungan di Fasilitas Kesehatan Tingkat Pertama (FKTP) yang didiagnosis hipertensi pada kelompok umur antara 35-59 tahun, yaitu sebesar 73.639, sedangkan di Kota Malang sebesar 36,3\% kasus hipertensi (Kemenkes, 2016; Riskesdas, 2013).

Terjadinya hipertensi dipengaruhi oleh berbagai faktor yaitu yang dapat dikendalikan maupun yang tidak dapat dikendalikan. Faktor yang tidak dapat dikendalikan meliputi jenis kelamin, umur, genetik, dan ras. Adapun yang dapat dikendalikan, seperti, pola makan, kebiasaan olahraga, konsumsi garam, kopi, alkohol dan stres. Kedua faktor risiko tersebut perlu ada bersama-sama 
dalam proses terjadinya hipertensi (common underlying risk factor), karena satu faktor risiko saja belum cukup menyebabkan hipertensi

(Artiyaningrum, 2015). Risiko hipertensi dipengaruhi oleh usia, genetik, obesitas, konsumsi lemak tinggi dan kurangnya aktivitas fisik, oleh karena itu penting dilakukan

pemeriksaan secara berkala dimasyarakat untuk mendeteksi gejala hipertensi agar terhindar dari resiko komplikasi penyakit tersebut (Ramnarine M, 2018).

Pemeriksaan yang dilakukan dimasyarakat salah satu kelurahan di Kabupaten Malang (Kelurahan CK) merupakan salah satu pelaksanaan bakti sosial yang menitikberatkan kepada upaya preventif dan kuratif. Kegiatan pengabdian ini bertujuan untuk membantu masyarakat untuk mendekatkan pelayanan kesehatan dengan target terciptanya masyarakat sehat, sejahtera serta mempermudah menikmati fasilitas kesehatan yang tersedia tanpa menunggu proses administrasi yang panjang disetiap pelayanan kesehatan yang diberikan.

Masih tingginya angka kesakitan dimasyarakat menjadi poin utama dilakukan pemeriksaan kesehatan dengan pendekataan berbasis komunitas secara cermat dan tepat untuk mengatasi persoalan yang berhubungan dengan deteksi dini dan pencegahan penyakit pada

\section{Analisis Situasi diwilayah Binaan}

Kegiatan pemeriksaan kesehatan ini melibatkan seluruh warga di Salah satu Kelurahan di Kota Malang (Keluraha CK). Warga yang datang berpartisipasi merupakan warga Kelurahan ini dari 11 RW (Rukun komunitas yang memiliki resiko terjadinya hipertensi (sulaiman, 2018 ), meskipun fasilitas kesehatan sudah memadai terbukti banyaknya klinik dan pelayanan primer dimasyarakat, namun kebanyakan masyarakat masih memiliki persepsi bahwa "berobat itu mahal" dan harus

membayar, akibatnya malas memeriksakan kesehatan secara rutin. Dukungan informasi terkait dengan pencegahan hipertensi juga penting diberikan untuk meningkatkan pemahaman tentang kesehatan secara komprehensif pada masyarakat (Ali A and Katz, 2015).

Peran serta tim pengabdian Fakultas Kedokteran Universitas Islam Malang menjadi penting dalam upaya meningkatkan derajat kesehatan dimasyarakat, maka diperlukan tindakan nyata dari berbagai pihak untuk terjun secara langsung ketengah-tengah masyarakat. Tindakan nyata tersebut dapat berupa pemberian pelayanan

kesehatan secara cuma-cuma. Pelayanan di bidang kesehatan merupakan salah satu bentuk pelayanan yang paling banyak dibutuhkan oleh masyarakat agar terhindar dari penyakit hipertensi. Selain itu kegiatan ini memberikan manfaat bagi masyarakat untuk meningkatkan kualitas hidup menjadi lebih baik dan lebih sehat. 
lingkungan, PSM (Pekerja Sosial Masyarakat), Gapoktan (Gabungan Kelompok Tani dan Nelayan), KKB (Kader Keluarga Berencana), BKB (Bina Keluarga Balita), WKSBM

(Wahana Kesejahteraan Sosial Berbasis Masyarakat), Tokoh Masyarakat, Gerdu Taskin, PLKB, Dasawisma, PAUD (Pendidikan Anak Usia Dini), TK, Modin, Satgas Linmas, dan lain-lain. Keunggulan wilayah ini dibandingkan dengan kelurahan lain yaitu wahana belajar alam tentang bercocok tanam organik dan kolaborasi antara hewan peliharaan dengan tanaman dengan hasil olahan sayuran organik itu berupa gorengan tahu sayur dan minum susu kedelai (Anonym, 2016; Anonym, 2018).

Pelaksanaan kegiatan ini

untuk mendekatkan pelayanan kesehatan dengan masyarakat yang di lakukan di Balai Desa Kelurahan setempat, dengan jumlah Peserta sebanyak 150 warga dari $11 \mathrm{RW}$ yang tersebar diwilayah ini. Pemilihan diwilayah ini penting dijadikan daerah binaan secara terpadu dikarenakan masyarakat cenderung masih "menganggap

\section{HASIL PELAKSANAAN KEGIATAN}

Berdasarkan tabel 1. dapat diketahui bahwa dari 150 partisipan yang mengikuti kegiatan pemeriksaan kesehatan diantaranya adalah lakilaki sebanyak $33,3 \%$ dan perempuan $(66,7 \%)$ dengan jumlah usia terbanyak yaitu 51-60 tahun 48 partisipan (32\%). Mayoritas masyarakat yang terlibat dalam kegiatan ini adalah petani, pedagang (wiraswasta) dan pekerja lepas dengan status keluarga menengah pengobatan lebih baik dari pencegahan penyakit", meskipun tinkat kesadaran akan kesehatan

tinggi terlihat dari antusias masyarakat yang tinggi dalam pemeriksaan kesehatan. Tujuan program tidak hanya pemeriksaan kesehatan saja akan tetapi upaya pencegahan berkelanjutan tetap dilakukan agar masyarakat memiliki umur harapan hidup yang lebih baik guna meningkatkan derajad kesehatan secara optimal. Pendekatan yang diberikan merupakan implementasi dari upaya kuratif, promotif dan preventif bagi masyarakat yang ingin mendeteksi kesehatan secara langsung. Kegiatan ini terlaksana atas kerjasama dengan mitra bidang kesehatan seperti

Puskesmas, Kelurahan, tokok masyarakat, serta masyarakat sekitar yang telah partisipasi mendukung pelaksanaan secera keseluruhan. Kegiatan pemberdayaan ini juga diharapkan mampu memberikan kesejahteraan keluarga melalui upaya pemberian informasi kesehatan secara verbal "konseling" disertai tanya jawab berkaitan dengan keluhan penyakit yang diderita.

kebawah, sedangkan penyakit yang terdiagnosa kebanyakan adalah Hipertensi dengan penyakit penyerta lainnya seperti mialgia, penglihatan kabur, spalgia, pembesaran gondok serta dermatitis. Saat pemeriksaan dibalai desa setempat pasien

(partisipan) dianjurkan untuk melakukan pemeriksaan lanjutan kepelayanan Rumah sakit dan

Puskesmas terdekat untuk memastikan tegaknya diagnosa. 


\section{Distribusi frekuensi partisipan dalam kegiatan pemeriksaan kesehatan}

Tabel 1. Karakteristik partisipan dalam kegiatan pengabdian masyarakat

\begin{tabular}{lcc}
\hline Karakteristik & Jumlah $(\mathbf{n = 1 5 0})$ & Presentasi $(\%)$ \\
\hline Jenis Kelamin & & \\
- Laki-laki & 50 & 33,3 \\
- Perempuan & 100 & 66,7 \\
Umur & & \\
- <30 tahun & 3 & 2 \\
- 31-40 tahun & 15 & 10 \\
- 41-50 tahun & 26 & 17,3 \\
- 51-60 tahun & 48 & 32 \\
- 61-70 tahun & 40 & 26,7 \\
- > 71 tahun & 18 & 12 \\
Penyakit yang diderita & & \\
- Normal & 24 & 16 \\
- Gondok & 2 & 1,4 \\
- Hipertensi & 120 & 80 \\
- Non hipertensi/Diabetes Melitus & 4 & 2,6 \\
\hline
\end{tabular}

\section{Pemeriksaan kesehatan}

\section{Hasil Pemeriksaan Tekanan Darah}

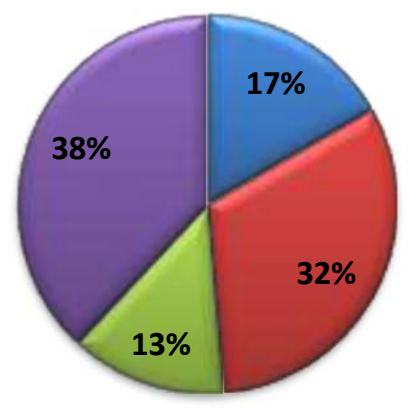

Normal $<120$ dan $<80$

Prehipertensi 120-139 atau 80-89

Hipertensi tahap I 140-159

atau 90-99

Hipertensi tahap II $\geq 160$ atau $\geq 100$

\section{Diagram Pie 1. Hasil pemeriksaan Tekanan Darah}

Hasil pemeriksaan kesehatan pada diagram pie 1. diatas menunjukkan bahwa sebanyak 150 warga yang data dalam kegiatan bakti sosial masyarakat yang ada dikelurahan Cemorokandang terdiagnosa masih tingginya angka kesakitan terutama hipertensi pada usia 51-60 tahun sebanyak 48\% sesuai standar dalam pedoman tatalaksana hipertensi menggunakan standar JNC 7 (Joint National Commitee on the prevention, detection, evaluation and treatment 
of high blood pressure) yaitu pre hipertensi sebanyak 48 (32\%), hipertensi tahap 1 yaitu $20(13,3 \%)$, hipertensi tahap 2 sebanyak 57 $(38 \%)$, juga terdapat $4(2,7 \%)$ penderita terdiagnosa Diabetes melitus (DM). Gejala seperti DM juga ditemukan saat pemeriksaanya gula darah sewaktu meskipun menunjukan kondisi normal namun terdiagnosa hipertensi juga menderita DM terdeteksi sebanyak 4 orang dengan gejala penyerta seperti linu dan tangan kiri sakit, kesemutan dan penanda lainnya.

Pemeriksaan dilakukan secara teratur dan bertahap disetiap partisipan. Peralatan medis yang digunakan seperti tensi, kit gula darah sewaktu, lemak darah, gula darah, asam urat serta steteskop. Masyarakat terlihat antusia untuk

mengikuti kegiatan secara keseluruhan terbukti dengan banyaknya jumlah kunjungan saat pelaksanaan pengabdian diwilayah ini.

\section{Konseling pencegahan penyakit di daerah Binaan}

Pelaksanaan konseling dilakukan setelah kegiatan pemeriksaan kesehatan. Media yang digunakan seperti media brosur anjuran hidup bersih dan sehat serta himbauan dan anjuran menjaga kesehatan terusmenerus dinformasikan (Adams JR,

2010). Kegiatan konseling merupakan upaya preventif yang penting dilakukan dengan harapan terjadi penurunan prevalensi kasus hipertensi yang didukung oleh kesadaran berperilaku sehat melalui perbaikan gizi, kontrol tekanan darah serta menjaga pola hidup bersih dan sehat serta mengkonsumsi makanan bergizi. Peningkatan kesadaran melalui penyampaian informasi berulang yang direspon melalui kegiatan diskusi dan tanya jawab diharapkan mampu memberikan pemahaman pentinnya menjaga kesehatan. Persepsi bahwa berobat itu mahal juga diluruskan dengan

pemberian pemahaman bahwa mencegah dengan cara sederhana seperti olah raga, peningkatan aktivitas fisik, mengurangi resiko hipertensi tidak merokok dan mengurangi konsumsi lemak dan garam diharapkan mampu mencegah penyakit ini. Kondisi spritual juga penting ditingkatkan tidak hanya informasi kesehatan jasmani namun rohani juga dijaga agar selalu berperilaku positif, tidak marah atau meningkatkan kegiatan yang bermanfaat mampu menekan tindakan negatif yang merusak hati dan pikiran menjadikan upaya penting yang dilakukan saat konseling berlangsung (Puchalsky, 2001).

Masyarakat yang terlibat (partisipan) dikegiatan ini menunjukan antusias bertanya untuk mengatur pola makan dan konsumsi obat hipertensi sebagai bentuk respon timbal balik yang bermanfaat bagi perkembangan kesehatanya. Anjuran yang penting diberikan saat diskusi yaitu berupaya secara mandiri menjaga kesehatan diri dengan melakukan pemeriksaan rutin atau kontrol dipusat layanan kesehatan primer sebagai bentuk upaya mewujudkan keluarga sehat dan sejahtera. 


\section{Analisis SWOT Pelaksanaan Pembinaan Masyarakat}

Tabel 1. Analisis SWOT Pelaksanaan Pembinaan Masyarakat

\begin{tabular}{|c|c|c|c|c|}
\hline No. & $\begin{array}{c}\text { Strengths } \\
\text { (Kekuatan) }\end{array}$ & $\begin{array}{c}\text { Weakness } \\
\text { (Kelemahan) }\end{array}$ & $\begin{array}{c}\text { Opportunities } \\
\text { (Kesempatan) }\end{array}$ & $\begin{array}{c}\text { Treath } \\
\text { (Tantangan) }\end{array}$ \\
\hline 1. & $\begin{array}{lr}\begin{array}{l}\text { Dukungan } \\
\text { birokrasi }\end{array} & \begin{array}{r}\text { secara } \\
\text { pelalui }\end{array} \\
\text { perijinan oleh } & \text { Lurah, } \\
\text { Ketua RT dan RW serta } \\
\text { perangkat yang } & \text { ada di } \\
\text { wilayah ini } & \text { termasuk } \\
\text { tokoh } & \text { masyarakat } \\
\text { setempat } & \text { serta } \\
\text { mendapat persetujuan } \\
\text { dan perijinan } \\
\begin{array}{l}\text { diberikan yng } \\
\text { kesbanglinmas } \\
\text { Malang Kota } \\
\text { pendukung kegiatan }\end{array} \\
\end{array}$ & $\begin{array}{l}\text { Adanya budaya masyarakat } \\
\text { yang mengasumsikan } \\
\text { bahwa "Menjaga kesehatan } \\
\text { lebih baik dari pada } \\
\text { mengobati" merupakan } \\
\text { anjuran yang belum } \\
\text { dilaksanakan sepenuhnya } \\
\text { oleh individu maupun } \\
\text { masyarakat. }\end{array}$ & $\begin{array}{l}\text { Minat masyarakat yang } \\
\text { tinggi }\end{array}$ & 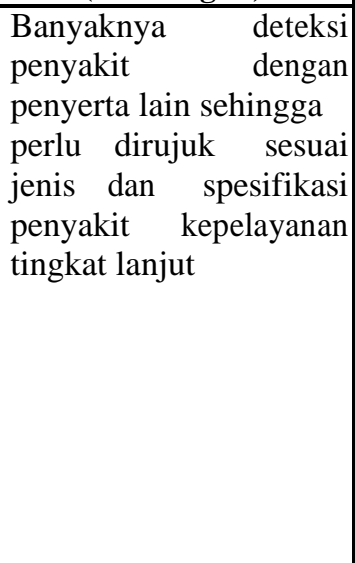 \\
\hline 2. & $\begin{array}{l}\text { Hubungan cukup baik } \\
\text { dengan masyarakat } \\
\text { setempat terlihat } \\
\text { antusias masyarakat } \\
\text { yang datang ke lokasi } \\
\text { pemeriksaan cukup } \\
\text { banyak }\end{array}$ & $\begin{array}{l}\text { Jadwal antara pelaksanaan } \\
\text { kegiatan dengan satu dan } \\
\text { lainya yang berbeda seperti } \\
\text { aktivitas akademik dan } \\
\text { masyarakat bekerja } \\
\text { masyarakat kegiatan yang } \\
\text { tidak sama }\end{array}$ & $\begin{array}{l}\text { Penerimaan tokoh } \\
\text { masyarakat setempat } \\
(\mathrm{RT}) \text { cukup baik }\end{array}$ & $\begin{array}{l}\text { Masih } \\
\text { terdapatmasyarakat } \\
\text { yang antri saat } \\
\text { penyelenggaraan } \\
\text { sudah selesai }\end{array}$ \\
\hline 3. & $\begin{array}{l}\text { Pengalaman tim } \\
\text { pelaksanaan kegiatan } \\
\text { pengabdian masyarakat } \\
\text { sebagai upaya deteksi } \\
\text { hipertensi sudah cukup } \\
\text { baik }\end{array}$ & $\begin{array}{l}\text { Keterbatasan waktu } \\
\text { pelaksanaan diperkirakan } \\
\text { hanya } 1 \text { hari sehingga } \\
\text { jumlah sehingga peserta } \\
\text { yang tidak mendaptar } \\
\text { sebelum acara akan } \\
\text { kesulitan mengantri dengan } \\
\text { batas waktu yang } \\
\text { ditetapkan }\end{array}$ & $\begin{array}{l}\text { Penerimaan orang tua } \\
\text { terhadap kegiatan } \\
\text { cukup baik }\end{array}$ & $\begin{array}{l}\text { Terdapat lansia yang } \\
\text { harus didampingi } \\
\text { keluarga karena } \\
\text { fasilitas terbatas }\end{array}$ \\
\hline 4. & $\begin{array}{l}\text { Tersedianya Fasilitas } \\
\text { obat yang cukup } \\
\text { memadai serta } \\
\text { didukung oleh tim } \\
\text { farmasi FK Unisma }\end{array}$ & $\begin{array}{l}\text { Perlu pengolahan laporan } \\
\text { yang rapi dan terstruktur } \\
\text { untuk memudahkan } \\
\text { pelacakan data dari hasil } \\
\text { kegiatan }\end{array}$ & $\begin{array}{l}\text { Ketersediaan tempat } \\
\text { pelaksanaan kegiatan } \\
\text { yang luas memudahkan } \\
\text { dalam pemeriksaan } \\
\text { kesehatan }\end{array}$ & $\begin{array}{l}\text { Pemahaman tentang } \\
\text { pengobatan tindak } \\
\text { lanjut penting } \\
\text { dilakukan sebagai } \\
\text { upaya alternatif } \\
\text { pencegahan penyakit }\end{array}$ \\
\hline 5. & \begin{tabular}{llr}
\multicolumn{3}{l}{ Keteraturan dan disiplin } \\
budaya antri & sudah \\
cukup baik & untuk \\
memudahkan & \\
pemeriksaan & kesehatan \\
secara baik &
\end{tabular} & $\begin{array}{l}\text { Masih memerlukan } \\
\text { kedisiplinan dalam tata } \\
\text { kelola informasi atau } \\
\text { berkas rekam medis sesuai } \\
\text { urutan nama dan wilayah }\end{array}$ & $\begin{array}{l}\text { Perolehan izin dari RT, } \\
\text { Lurah, serta Puskesmas } \\
\text { setempat }\end{array}$ & $\begin{array}{l}\text { Masih terdapat } \\
\text { masyarakat yang harus } \\
\text { dibimbing terkait } \\
\text { penggunaan obat yang } \\
\text { diberikan akibat akibat } \\
\text { tingkat usia yang } \\
\text { sudah lanjut }\end{array}$ \\
\hline
\end{tabular}




\section{KESIMPULAN}

Berdasarkan hasil diagnosa komunitas pada wilayah pengabdian masyarakat menunjukkan bahwa sebagian besar warga terdiagnosa hipertensi tahap 2 sebanyak 57 (38\%) dengan rentang usia antara 51-

\section{SARAN}

Perlu dilakukan pembinaan masyarakat berkelanjutan dengan melibatkan pihak terkait seperti Puskesmas maupun klinik yang dapat

\section{DAFTAR PUSTAKA}

Adams RJ. 2010. Improving health outcomes with better patient understanding and education. Risk Manage Healthc Policy. 2010; 3: 61-72.

Published online 2010 Oct 14. doi: 10.2147/RMHP.S7500.

Ali A and Katz DL. 2015. Disease

Prevention and Health

Promotion:

How Integrative Medicine Fits.

Am J Prev Med. 2015

November ; 49(5 0 3): S230

S240.

doi:10.1016/j.amepre.2015.07.

019

Anonym. 2016.Profil Kelurahan Cemorokandang Kota Malang. Diakses pada tanggal 24 April 2018 di https://ngalam.co/2016/03/28/p rofil-kelurahancemorokandang-kecamatankedungkandang-kota-malang Anonym. 2018. Pemerintah Kota Malang. Diakses pada tanggal
60 tahun yang cenderung beresiko terjadinya komplikasi penyakit jika tidak dikendalikan dan dicegah melalui pola hidup sehat dan lebih memperhatikan asupan gizi seimbang guna meningkatkan kualitas hidup sejahtera.

membantu masyarakat secara langsung dan cepat dalam penangan penyakit dengan gejala komplikasi. Peran tokoh masyarakat dan tenaga kesehatan mampu menjadi ujung tombak pemberdayaan masyarakat guna meningkatkan kesehatan dan kesejahteraan diwilayah setempat.

$24 \quad$ April $2018 \quad$ di http://kelcemorokandang.malan gkota.go.id.

Artiyaningrum, B, 2015. Faktorfaktor yang Berhubungan dengan Kejadian Hipertensi

Tidak Terkendali pada Penderita yang Melakukan Pemeriksaan Rutin Di Puskesmas Kedungmundu Kota Semarang Tahun 2014. Semarang.

Badan Penelitian dan Pengembangan Kesehatan Kementerian Kesehatan Republik Indonesia, 2013. Riset Kesehatan Dasar (Riskesdas 2013). Kementerian Kesehatan Republik Indonesia. Diakses tanggal 24 April 2018 di

http://www.depkes.go.id/resour ces/download/general/Hasil\%2 0Riskesdas\%202013.pdf .

Kementerian Kesehatan Republik Indonesia (Kemenkes RI) 2013. Laporan Riset Kesehatan 
Dasar 2013.

Puchalsky CM. 2001. The role of spirituality in health care. Baylor University Medical Center Proceedings Volume 14, Number 4. Proceedings.

Ramnarine M. 2018. Blood Pressure Assessment. Diunduh dari pada tanggal 11 juli 2019.

https://emedicine.medscape.co m/article/1948157-overview
Sulaiman, M R 2018, Hipertensi Jadi Penyakit Paling Banyak Dialami Penduduk RI. Diakses pada tanggal 30 Agustus 2018 di

https://m.detik.com/health/berit a-detikhealth/d-

4101603/semester-i-2018hipertensi-jadi-penyakitpaling-banyak dialamipenduduk-ri. 2018 